\title{
JUDICIAL DISCRETION IN CRIMINAL PROCEEDINGS
}

\author{
Sergey N. Zelensky \\ Central Ukrainian State Pedagogical University named after Vladimir Vinnichenko, Kropyvnytskyi, Ukraine
}

Introduction: the resolution of a criminal case is essentially the central stage of criminal proceedings, where the judge concludes that the person brought to criminal responsibility is guilty on the basis of the interpretation and application of the law. The interpretation of criminal procedural rules and judicial discretion are linked to the enforcement process. It is possible to use evaluative concepts in law, the content of which is determined not by the law or regulation, but by the legal awareness of the subject of law enforcement. Purpose: to show the essence and importance of judicial discretion as an evaluative concept in criminal proceedings; to disclose the content of the grounds of discretion, by which it is proposed to understand the objectively existing elements of the legal system, which directly determine the possibility of choosing one of the legally permitted options for the enforcement. Methods: the methodological framework for the study is the general scientific (dialectical, systemic, logical, etc.) and the specific scientific (formal-legal, comparative law, historical-legal, etc.) research methods. Results: judicial discretion is excluded when choosing between a legal and illegal decision. An illegal decision is not a form of discretion, but only arbitrariness. Discretion is subject to the gaps and conflicts of law. The proper justification of court decisions is not limited to citing the provisions of the law. The law may lack a rule regulating a specific social attitude due to their extremely dynamic development. The absence of a rule excludes judicial discretion. In this case, it will actually be a manifestation of arbitrariness, since all the grounds for discretion are somehow connected with the interpretation of the legal norm. Conclusions: the specification of discretion implies a choice of different legal alternatives. Under these alternatives, the court chooses the most appropriate option in a particular criminal proceeding, bound by the general principles of law. The court is bound by the requirements of legality, validity and motivation of the decision.

Key words: judicial discretion, interpretation, evaluative concepts, discretion, discretion, discretional powers.

Citation. Zelensky S.N. Judicial Discretion in Criminal Proceedings. Legal Concept, 2019, vol. 18, no. 2, pp. 74-78. (in Russian). DOI: https://doi.org/10.15688/lc.jvolsu.2019.2.11

УДК 343.16

ББК 67.410 .201

Дата поступления статьи: 05.03.2019

Дата принятия статьи: 01.04.2019

\section{СУДЕЙСКАЯ ДИСКРЕЦИЯ В УГОЛОВНОМ СУДОПРОИЗВОДСТВЕ}

\author{
Сергей Николаевич Зеленский \\ Центральноукраинский государственный педагогический университет им. Владимира Винниченко, \\ г. Кропивницкий, Украина
} Введение: разрешение уголовного дела по существу является центральным этапом уголовного произ-
водства, где судья делает свой вывод о виновности лица, привлекаемого к уголовной ответственности на
основании толкования и применения норм права. Толкование уголовных процессуальных норм и судебное
усмотрение связаны между собой процессом правоприменения. Возможно использование в законе оце-
ночных понятий, содержание которых определяется не законом или нормативным актом, а правосознанием
субъекта правоприменения. Цель: показать сущность и значение судейского усмотрения как оценочного
понятия в уголовном судопроизводстве; раскрыть содержание оснований усмотрения, под которыми пред-
лагается понимать объективно существующие элементы правовой системы, которые непосредственно обус-
ловливают возможность выбора одного из юридически разрешенных вариантов правоприменительного
решения. Методологическую основу работы составили общенаучные (диалектический, системный, логи-
ческий и др.) и частнонаучные (формально-юридический, сравнительно-правовой, историко-правовой и др.) 
методы исследования. Результаты: судейское усмотрение исключается при выборе между законным и незаконным решением. Незаконное решение не является формой проявления усмотрения, а лишь произволом. Свобода усмотрения зависит от наличия пробелов и коллизий в законодательстве. Должное обоснование судебных решений не ограничивается цитированием положений закона. В законе может отсутствовать норма, регламентирующая конкретное общественное отношение, вследствие чрезвычайно динамичного их развития. Отсутствие нормы исключает судейское усмотрение. В этом случае оно фактически будет проявлением произвола, поскольку все основания усмотрения так или иначе связаны с толкованием правовой нормы. Выводы: конкретизация относительно свободы усмотрения предполагает наличие выбора различных законных альтернатив. В рамках этих альтернатив суд избирает наиболее приемлемый вариант в конкретном уголовном производстве, будучи связанным общими принципами права. Суд связан при этом требованиями законности, обоснованности и мотивирования решения.

Ключевые слова: судейское усмотрение, толкование, интерпретация, оценочные понятия, свобода усмотрения, дискреция, дискреционные полномочия.

Цитирование. Зеленский С. Н. Судейская дискреция в уголовном судопроизводстве // Legal Concept $=$ Правовая парадигма. - 2019. - Т. 18, № 2. - C. 74-78. - DOI: https://doi.org/10.15688/lc.jvolsu.2019.2.11

\section{Введение}

Разрешение уголовного дела по существу является центральным этапом уголовного производства, где судья делает свой вывод о виновности лица, привлекаемого к уголовной ответственности на основании толкования и применения норм права. Толкование уголовных процессуальных норм и судебное усмотрение связаны между собой процессом правоприменения. Возможно использование в законе оценочных понятий, содержание которых определяется не законом или нормативным актом, а правосознанием субъекта правоприменения. При этом соблюдается разумный баланс между публичными и частными интересами. Разного рода аргументы политического, нравственного и идеологического характера не противопоставляются закону в ходе его толкования и применения [5, с. 280].

В соответствии со ст. 94 Уголовного процессуального кодекса Украины законодатель устанавливает возможность судейской дискреции, поскольку следственный судья, суд, а также следователь и прокурор по своему внутреннему убеждению, которое основано на всестороннем, полном и непредвзятом исследовании всех обстоятельств уголовного производства, руководствуясь законом, оценивают каждое доказательство с точки зрения относимости, допустимости, достоверности, а совокупность собранных доказательств - с точки зрения достаточности и взаимосвязи для принятия соответствующего процессуального решения.
Существование норм права, содержащих оценочные понятия, указания наиболее общих признаков, свойств, качеств, связей и отношений предметов, явлений, действий, процессов, предполагает самостоятельный выбор участником правоотношений варианта поведения (оценку судом) по конкретной ситуации в определенной социальной среде и в строго определенное время с учетом внутреннего убеждения. А. Барак определяет судейскую дискрецию или судейское усмотрение как полномочия, предоставленные лицу, обладающему властью, выбирать между двумя или более альтернативами, когда каждая из них является законной [1, с. 13-14].

Примеров норм, содержащих оценочные понятия, немало. Проблемные ситуации возникают, когда нормы права не дают возможность суду действовать по своему усмотрению, однако норма может быть неоднозначной по содержанию. Это вынуждает суд вносить в свою деятельность элементы усмотрения. В законе может отсутствовать норма, регламентирующая конкретное общественное отношение, вследствие чрезвычайно динамичного их развития. Отсутствие нормы исключает судейское усмотрение. В этом случае оно фактически будет проявлением произвола, поскольку все основания усмотрения так или иначе связаны с толкованием правовой нормы. Основаниями усмотрения следует считать объективно существующие элементы правовой системы, которые непосредственно обусловливают возможность выбора одного из юридически разрешенных вариантов правоприменительного решения. 


\section{Понятие и содержание дискреционных полномочий суда}

Дискреционные полномочия суда признаются и Европейским судом по правам человека - ЕСПЧ (в частности, дело «Довженко против Украины») [2]. ЕСПЧ в своих решениях отмечает, что определение законности, объема, способов и пределов применения свободы оценивания представителями судебных органов должно соответствовать принципу верховенства права.

Судейская дискреция исключается в случае отказа органа расследования открыть материалы негласных следственных розыскных действий (далее - НСРД), что является основанием для признания таких доказательств недопустимыми. Соответственно и судья не может положить такие доказательства в основу обвинительного приговора. Согласно ч. 2 ст. 290 УПК Украины прокурор или следователь по его поручению обязаны предоставить для ознакомления материалы досудебного расследования, которые имеются в его распоряжении, в том числе любые доказательства, которые сами по себе или в совокупности с другими доказательствами могут быть использованы для подтверждения невиновности или меньшей степени виновности обвиняемого, или способствовать смягчению его наказания. Стороны уголовного производства обязаны открыть друг другу дополнительные материалы, полученные до судебного разбирательства или во время его проведения. Если сторона уголовного производства откажет в открытии материалов, суд не имеет право допустить сведения, содержащиеся в них, в качестве доказательств (ч. 11, 12 ст. 290 УПК Украины).

Проверка доказательств с целью определения их допустимости является важнейшей гарантией обеспечения прав и свобод человека и гражданина в уголовном производстве и принятия законного и справедливого решения по делу [6, с. 147]. Доказательствами в уголовном производстве являются фактические данные, полученные в предусмотренном УПК Украины порядке. Процессуальными источниками доказательств являются показания, вещественные доказательства, доку- менты, заключения экспертов (ч. 2 ст. 84 УПК Украины).

\section{Состязательность уголовного процесса как основа судейского усмотрения}

Конституция Украины устанавливает, что обвинение не может основываться на доказательствах, полученных незаконным путем, а также на предположениях. Так, главной обязанностью государства провозглашено обеспечение прав и свобод человека, а следовательно, правоохранительные органы и суд при установлении обстоятельств совершенного преступления во время досудебного расследования и судебного рассмотрения в уголовном производстве обязаны соблюдать гарантии прав и свобод человека и гражданина, закрепленные в Конституции и других законах Украины. Существенным нарушением прав и основоположных свобод, в частности, являются осуществление процессуальных действий, требующих предварительного разрешения суда, без такого разрешения или с нарушением его существенных условий.

Согласно ч. 1 ст. 94 УПК Украины суд должен оценить каждое доказательство с точки зрения его относимости, допустимости, достоверности. Так, осуществление проверки доказательств с целью определения их допустимости, если сторона защиты ставит их под сомнение, является обязанностью суда.

Защитники, как правило, инициируют в суде вопрос допустимости доказательств стороны обвинения и необходимости рассекречивания соответствующих материальных носителей информации по мотивам их проверки. Если сторона защиты не ставит под сомнение допустимость доказательств, которые подтверждаются неоткрытыми материалами, то и суд по собственной инициативе не сможет поставить их под сомнение.

Исследованию подлежат разрешения на проведение негласных следственных (розыскных) действий (далее - НСРД). В ст. 246 УПК Украины сказано, что в решении о проведении НСРД указывается срок его проведения и лицо, которое его проводит. Исследовать сведения, содержащиеся в материалах НСРД, даже если они свидетельствуют о совершении преступления, в таком случае нет необходимости. 


\section{Ограничения судейской дискреции} в уголовном судопроизводстве

Верховный Суд Украины (далее - ВСУ) высказался по поводу проблематики проведения оперативно-розыскных действий до внесения сведений в ЕРДР и открытия всех материалов производства в порядке ст. 290 УПК Украины. Непредоставление для ознакомления материалов сторонами в порядке ст. 290 УПК Украины исключает судейскую дискрецию и является основанием для признания таких материалов недопустимыми в качестве доказательств. При этом открытию, кроме протоколов, в которых зафиксированы ход и результаты проведения определенных действий, в обязательном порядке подлежат и материалы, которые являются основанием проведения таких действий (определения, постановления, ходатайства), что обеспечивает возможность проверки стороной защиты и судом допустимости результатов таких действий в качестве доказательств. В противном случае неоткрытие материалов НСРД, а это касается и постановлений суда о предоставлении разрешения на их проведение, стороне защиты в порядке ст. 290 УПК Украины, является основанием для признания таких доказательств недопустимыми (постановление ВСУ от 16.03.2017 р. по делу № 5-364кс16).

ВСУ отметил, что непредоставление для ознакомления в порядке, определенном ст. 290 УПК Украины (открытие материалов другой стороне), дает все основания судам считать доказательства, полученные с нарушением требований УПК Украины, недопустимыми.

Важен вывод ВСУ о том, что никто не запрещает сторонам уголовного производства представлять в суде материалы, не открытые друг другу. Запрещено только суду допускать сведения, содержащиеся в них, как доказательства. Предоставление стороной обвинения в суде материалов, к которым не был предоставлен доступ стороне защиты, и приобщение их в качестве доказательств на стадии судебного рассмотрения нарушает право обвиняемого на защиту, поскольку вынуждает его защищаться от так называемых новых доказательств без предоставления достаточных возможностей и времени для их опровержения.
Следовательно, при таких условиях, когда стороне обвинения известны все доказательства, а сторона защиты не владеет информацией о них до завершения расследования, суд отмечает нарушения баланса интересов в уголовном процессе. Таким образом, по мнению ВСУ, непредоставление материалов сторонами друг другу в порядке ст. 290 УПК Украины по окончании предварительного расследования, а также дополнительных материалов, полученных до судебного разбирательства или во время его проведения, исключает судейскую дискрецию и является основанием для признания судом сведений, содержащихся в них, недопустимыми доказательствами.

Эта правовая позиция находит свое подтверждение в выводах Европейского суда по правам человека. В качестве примера можно привести дело «Раманаускас против Литвы» [3] и дело «Мирилашвили против России» [4]. Суды таким образом устанавливают способ получения доказательств вины лица, привлекаемого к уголовной ответственности, для выяснения вопроса о законности методов получения доказательств.

Рассекречиванием материалов НСРД занимается прокурор, поскольку доказательства допустимости доказательств являются его прямой обязанностью. Если же прокурор отказывается принять решение о рассекречивании, а сторона защиты настаивает на недопустимости доказательств, полученных в результате проведения НСРД, суд должен принимать во внимание содержание ч. 3, 4 ст. 17 УПК Украины и решить вопрос об их недопустимости.

\section{Выводы}

Судейское усмотрение исключается при выборе между законным и незаконным решением. Незаконное решение не является формой проявления усмотрения, а лишь произволом. Свобода усмотрения зависит от наличия пробелов и коллизий в законодательстве [7, с. 106]. Должное обоснование судебных решений не ограничивается цитированием положений закона. Конкретизация относительно свободы усмотрения предполагает наличие выбора различных законных альтернатив. В рам- 
ках этих альтернатив суд избирает наиболее приемлемый вариант в конкретном уголовном производстве, будучи связанным общими принципами права. Суд связан при этом требованиями законности, обоснованности и мотивирования решения.

\section{СПИСОК ЛИТЕРАТУРЫ}

1. Барак, А. Судейское усмотрение / А. Барак-М. : НОРМА, 1999. - 376 c.

2. Дело «Довженко против Украины» (заявление № 36650/03), Страсбург, 12 января 2012 г. Электрон. текстовые дан. - Режим доступа: http:// zakon.rada.gov.ua/laws/show/974_845/ (дата обращения: 05.02.2019). - Загл. с экрана.

3. Дело «Раманаускас против Литвы» (заявление № 74420/01), Страсбург, 5 февраля 2008 г. - Электрон. текстовые дан. - Режим доступа: https://roseurosud.org/r/st-6/st-6a-2/postanovlenie-espch-ramanauskas-protiv-litvy (дата обращения: 14.02.2019). - Загл. с экрана.

4. Дело «Мирилашвили против России» (заявление № 6293/04), Страсбург, 11 декабря 2008 г. Электрон. текстовые дан. - Режим доступа: https://roseurosud.org/r/st-6/st-6a-2/postanovlenieespch-ramanauskas-protiv-litvy (дата обращения: 18.02.2019). - Загл. с экрана.

5. Капліна, О. В. Правозастосовне тлумачення норм кримінально-процесуального права : монографія / О. В. Капліна. - Харьків : Право, 2008. - 296 с.

6. Соловьева, Н. А. Значение дифференциации оценочного терминологического аппарата для модернизации уголовно-процессуальной деятельности / Н. А. Соловьева // Вестник Волгоградского госу- дарственного университета. Серия 5, Юриспруденция. -2013 . - № 2 (19). - С. 143-150.

7. Соловьева, Н. А. Терминологическая проблема определения восстановительного правосудия / Н. А. Соловьева, В. М. Шинкарук // Вестник Волгоградского государственного университета. Серия 5, Юриспруденция. -2013. -№ 3 (20). - С. 104-109.

\section{REFERENCES}

1. Barak A. Judicial Discretion. Moscow, NORMA Publ., 1999.376 p. (in Russian).

2. Business "Dovzhenko against Ukraina" (2012). URL: http://zakon.rada.gov.ua/laws/show/ 974_845 (accessed 5 February 2019).

3. Business "Ramanauskas against Lithuania" (2008). URL: https://roseurosud.org/r/st-6/st-6a-2/ postanovlenie-espch-ramanauskas-protiv-litvy (accessed 14 February 2019).

4. Business of "Mirilashvili against Russia" (2008). URL: https://roseurosud.org/r/st-6/st-6a-2/ postanovlenie-espch-ramanauskas-protiv-litvy (accessed 18 February 2019).

5. Kaplina O.V. Right Applicable Interpretation of Norms of Law of Criminal Procedure. Kharkiv, Pravo Publ., 2008. 296 p. (in Ukrainian).

6. Solov'eva N.A. Value of Differentiation of an Estimated Terms Framework for Modernization of Criminal Procedure Activity. Science Journal of Volgograd State University. Jurisprudence, 2013, no. 2 (19), pp. 143-150. (in Russian).

7. Solov'eva N.A., Shinkaruk V.M. Terminological Problem of Definition of Recovery Justice. Science Journal of Volgograd State University. Jurisprudence, 2013, no. 3 (20), pp. 104-109. (in Russian).

\section{Information about the Author}

Sergey N. Zelensky, Associate Professor, Department of Legal Science, Central Ukrainian State Pedagogical University named after Vladimir Vinnichenko, Shevchenko St., 1, 25006 Kropyvnytskyi, Ukraine, sergei_zelenskii@mail.ru, https://orcid.org/0000-0002-0945-4485

\section{Информация об авторе}

Сергей Николаевич Зеленский, доцент кафедры правоведения, Центральноукраинский государственный педагогический университет им. Владимира Винниченко, ул. Шевченко, 1, 25006 г. Кропивницкий, Украина, sergei_zelenskii@mail.ru, https://orcid.org/0000-0002-0945-4485 